Bull. Mater. Sci., Vol. 2, Number 1, January 1980, pp. 35-41. (C) Printed in India.

\title{
Studies on a wear-resistant cast iron
}

\author{
N RANGANATHAN, MALUR N SRINIVASAN and N RAMAN \\ Department of Mechanical Engineering, Indian Institute of Science, \\ Bangalore 560012 \\ MS received 15 December 1979
}

\begin{abstract}
The possibility of developing a good wear-resistant cast iron with manganese and chromium as alloying elements in white cast iron was explored. The results indicate that it is possible, but the composition of the alloy in respect of manganese and chromium should be controlled within close limits to achieve the desired objective.
\end{abstract}

Keywords. Wear resistance ; white cast iron ; manganese ; chromium, molten alloy ; green sand moulds ; hardness ; wear rate ; austenite ; martensite ; pearlite ; alloy carbide.

\section{Introduction}

The combination of good wear resistance with adequate toughness is of paramount importance in abrasion-resistant components, as often serious impact loading conditions are encountered in these applications. It is to be realised that the above two requirements are basically in conflict and therefore a suitable compromise has to be arrived at in the choice of the material, with due regard to manufacturing ease and cost. At one end of the spectrum are materials like high manganese steel (Norman and Loeb 1948) which can withstand severe shock resistance and at the other, materials such as white cast inon which possess moderate wear resistance and poor shock resistance. However cast irons in general can be produced with relative ease and it is not surprising therefore that the drawback of white cast iron has been countered by the addition of nickel, chromium, copper and molybdenum as alloying elements in different proportions and combinations (Dodd and Govin 1974). The production of these alloys in our country however involves the use of imported elements in sufficiently large quantities so as to render the alloys difficult to produce on this account. Further these elements are very expensive. In this context an investigation was made by the present authors to explore the possibility of developing a wear-resistant cast iron using less expensive and locally available alloying elements in white cast iron. The results pertaining to wear resistance of these alloys are reported in this paper. 


\section{Experimental}

The following guidelines are available in respect of the composition for wear-resistant cast irons (Norman et al 1959) :

(i) Sufficient alloy content to suppress the formation of pearlite in a given casting.

(ii) Sufficient content of a carbide stabilising element to ensure freedom from graphite in the casting.

(iii) Sufficient carbon content to ensure optimum wear resistance.

(iv) Low silicon content to reduce the tendency for graphite formation and/or pearlite formation.

The elements chosen to suppress pearlite formation and graphitisation should be in such proportion as to permit control over retained austenite and the shape and distribution of the carbide phase.

Based on the above guidelines and easy availability manganese and chromium were chosen as the alloying elements. The nominal carbon and silicon contents were chosen as $3 \%$ and $1 \%$ respectively. The base charge consisting of carbon and silicon was initially prepared from steel scrap melted in a medium frequency induction furnace using additions of petroleum coke and ferrosilicon to get the desired composition. Ingotted bars of this base alloy were then melted in a basic lined arcfurnace and additions of ferro-manganese and ferro-chromium were made to get the desired composition. To minimise loss of these alloying elements melting was carried out using a basic reducing fiux. The molten alloy was poured at $1400^{\circ} \mathrm{C}$ into green sand moulds. For chemical analysis thin strips of the alloy were cast, crushed in a stamp mill and powdered using a drop hammer.

Wear tests were carried out using the experimental set-up shown in figure 1. The set-up consists of a specimen holder fixed to two arms which are carefully balanced by operating counterweights. The specimens were made to bear against 400 grit emery paper covering a rotating disc which was rotated at $1420 \mathrm{rpm}$. The nominal contact pressure on the specimen was kept at $1 \mathrm{~kg} / \mathrm{cm}^{2}$. The edges of the specimen were carefully bevelled to avoid tearing of the emery paper during the test. The duration of each test was fixed at $15 \mathrm{~min}$. The specimens were weighed in a monopan balance correct to a milligram, before and after the test to determine the loss of weight.

\section{Results and discussion}

In table 1 the chemical composition of the test specimens is listed while in table 2 the hardness and wean rate of the specimens are reported. The hardness values of the specimens have been plotted against the manganese content and the chromium content in figures 2 and 3 respectively.

It is evident from a study of these figures that

(i) in specimens containing nominally the same amount of chromium (range: $4 \cdot 85 \%$ to $5 \cdot 12 \%$ ) the hardness initially increases with the manganese content, reaches a maximum and decreases thereafter (figure 2), and 
Table 1. Chemical composition of manganese-chromium cast irons and other hardness.

\begin{tabular}{|c|c|c|c|c|c|}
\hline \multirow{2}{*}{ Code No. } & \multicolumn{4}{|c|}{$\%$ Composition } & \multirow{2}{*}{$\begin{array}{c}\text { Hardnes } \\
\boldsymbol{R}_{\boldsymbol{c}}\end{array}$} \\
\hline & $\mathrm{C}$ & $\mathbf{S i}$ & Mn & $\mathrm{Cr}$ & \\
\hline MN 2 & $3 \cdot 05$ & 0.97 & $14 \cdot 71$ & $4 \cdot 85$ & 48 \\
\hline MN 3 & $2 \cdot 99$ & $1 \cdot 08$ & $10 \cdot 36$ & $4 \cdot 9$ & 56 \\
\hline MN 5 & $3 \cdot 12$ & 0.94 & $4 \cdot 35$ & $4 \cdot 85$ & 42 \\
\hline MN 7 & $2 \cdot 95$ & 0.93 & $10 \cdot 6$ & $2 \cdot 95$ & 43 \\
\hline MN 8 & $3 \cdot 03$ & $1 \cdot 12$ & $10 \cdot 5$ & $6 \cdot 92$ & 48 \\
\hline
\end{tabular}

Table 2. Wear testing-experimental results.

\begin{tabular}{|c|c|c|c|c|c|}
\hline Code No. & $\begin{array}{l}\text { Weight } \\
\text { before } \\
\text { the test } \\
\text { (in g) }\end{array}$ & $\begin{array}{l}\text { Weight } \\
\text { after } \\
\text { the test } \\
\text { (in g) }\end{array}$ & $\begin{array}{l}\text { Weight } \\
\text { loss } \\
(W) \\
\text { (in mg) }\end{array}$ & $\begin{array}{c}\text { Hardness } \\
\text { in } \\
R_{0}\end{array}$ & $\begin{array}{c}\text { Wear } \\
\text { rate } \\
\mathrm{mg} / \mathrm{mt}\end{array}$ \\
\hline MN 2 & $47 \cdot 241$ & $47 \cdot 193$ & 48 & $48 \cdot 0$ & $3 \cdot 17$ \\
\hline MN 3 & $36 \cdot 905$ & $36 \cdot 873$ & 32 & $56 \cdot 0$ & $2 \cdot 18$ \\
\hline MN 5 & $35 \cdot 708$ & $35 \cdot 663$ & 45 & $42 \cdot 0$ & $2 \cdot 84$ \\
\hline MN 7 & $36 \cdot 420$ & $36 \cdot 375$ & 45 & $43 \cdot 0$ & $2 \cdot 78$ \\
\hline MN 8 & $37 \cdot 903$ & $37 \cdot 361$ & 42 & $48 \cdot 0$ & $2 \cdot 96$ \\
\hline
\end{tabular}

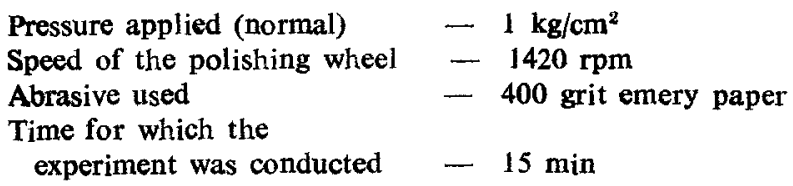

(ii) in specimens containing nominally the same amount of manganese (range: $10.2 \%$ to $10.5 \%$ ) a peak is again observed in the relationship between hardness and chromium content, but the relationship between the two variables is not as regulan as in the previous case (figure 3 ).

It is clear from tables 1 and 2 that an iron of composition $10.36^{\circ} \%$ manganese and $4.9 \%$ chromium wear rate and may be termed to have the optimum composition amongst the irons considered, in respect of wear resistance. The microstructure of this iron, shown in figure 4, throws light on the desirable shape and distribution of austenite-martensite in carbidic matrixin order to achieve good wear resistance. The reduction in hardness and increase in wear rate when there is a deviation from this composition may be explained with reference to figures 5 to 8 . It may be noted that figures 5 and 6 refer to microstructures of specimens where the manganese content has been varied around the optimum value $(10 \cdot 36 \%)$ when 


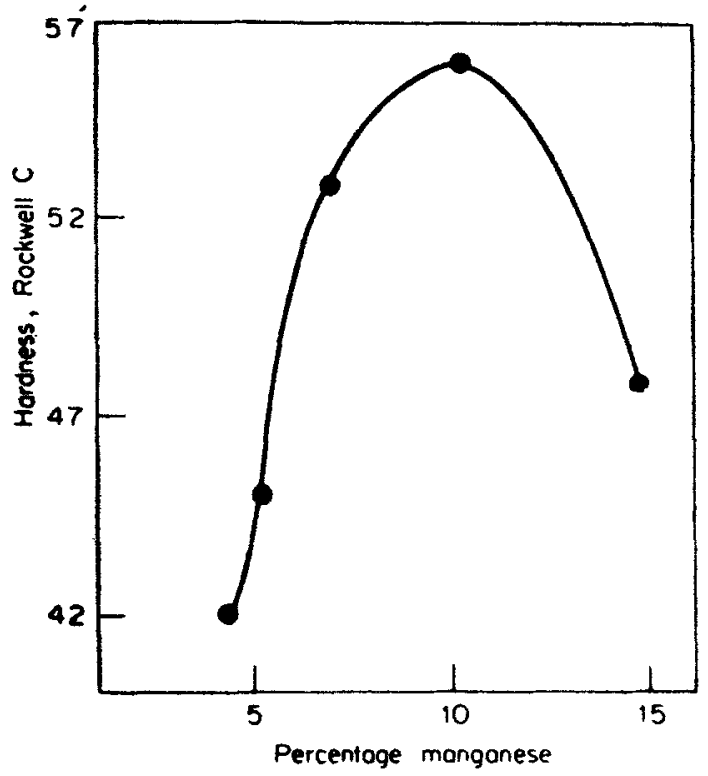

Figure 2. Relation between manganese content and hardness in $\mathrm{Mn}-\mathrm{Cr}$ irons.

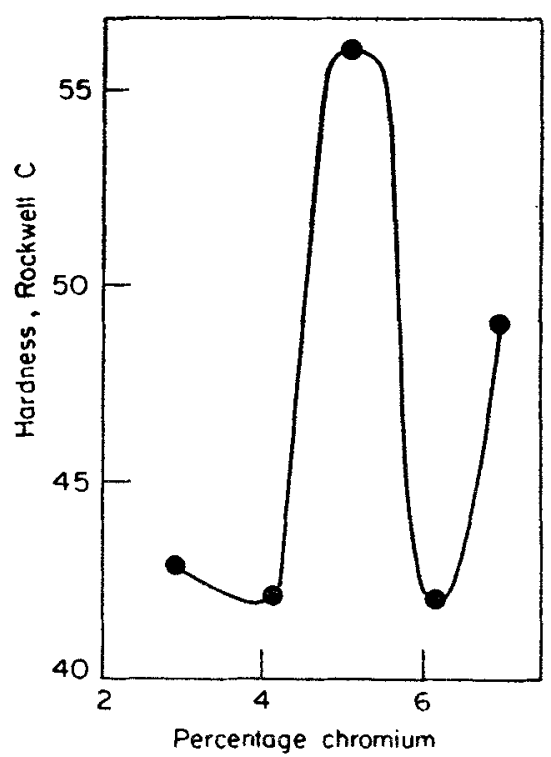

Figure 3. Relation between chromium content and hardness in $\mathrm{Mn}-\mathrm{Cr}$ irons.

the chromium content is nominally the same (about $5 \%$; while figures 7 and 8 refer to microstructures of specimens where the chromium content is varied while the manganese content is nominally the same (about 10.4\%). Referring to figure 5 it may be seen that the increased amount of manganese $(14 \cdot 71 \%)$ has caused over-stabilisation of austenite with the result that the optimal austeniticmartensitic structure of figure 4 (manganese $10.36 \%$ ) is not reproduced here. The amount of massive free carbide is also rather high. On the other hand when the manganese content is low (4.35\%) suppression of pearlite seems to be incomplete (figure 6). In figure 7 it may be seen that owing to lower chromium content $\left(2.95^{\circ}\right)$ there is again considerable amount of retained austenite leading to reduction in hardness and increased wear rate as compared to the optimum specimen (figure 4). When the chromium is increased to $6.92 \%$, an appreciable amount of alloy carbide, possibly $(\mathrm{Fe}, \mathrm{Cr})_{7} \mathrm{C}_{3}$ (Norman et al 1959) is revealed in the microstructure (figure 8). It is not clear at this stage why the hardness of this sample was lower despite the presence of this hard carbide. It is likely that this is due to the depletion of carbon in austenite owing to this carbide formation and the amount of alloy carbide formed being insufficient to compensate for this.

\section{Conclusion}

It is thus evident that it is possible to produce a reasonably good wear-resistant cast inon with manganese and chromium as alloying elements. However, the composition of the alloy in respect of chromium and manganese should be controlled within close limits to achieve the desired objective. 

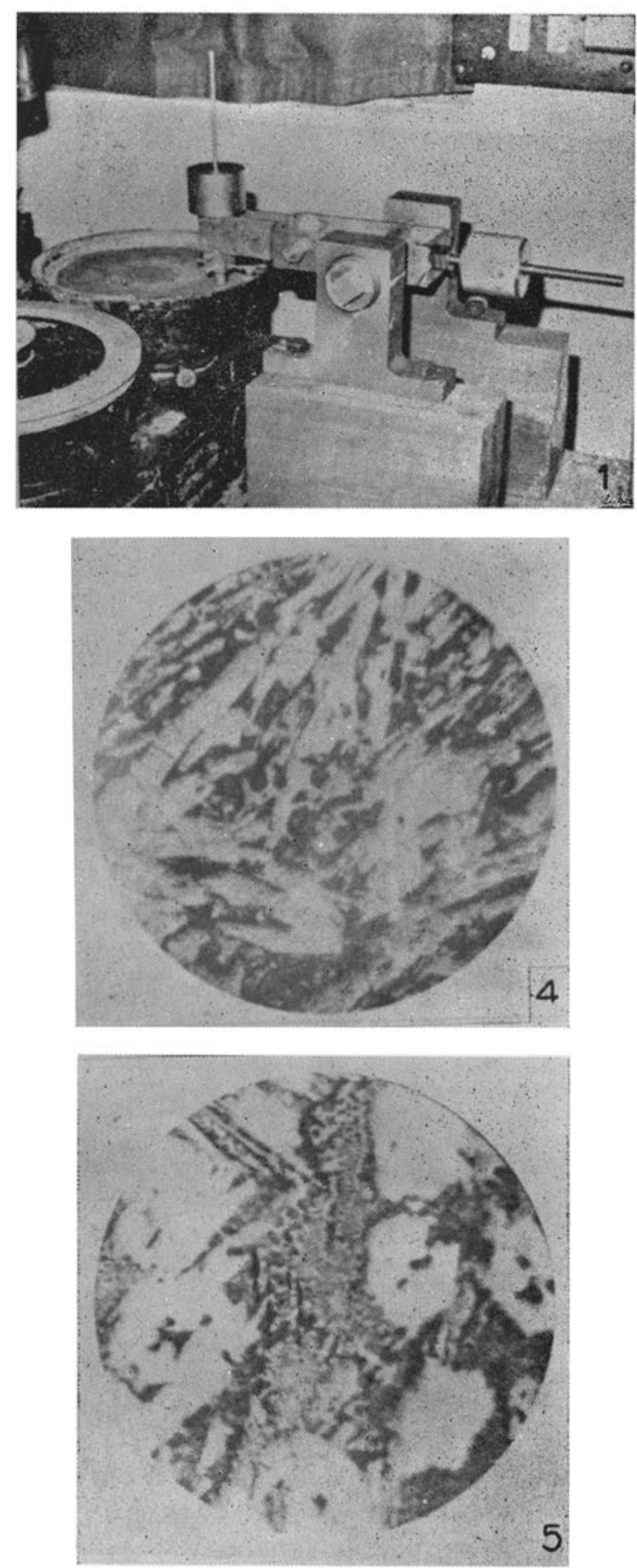

Figures 1, 4 and 5. 1. A view of the experimental set-up for wear testing. 4. Microstructure of cast iron with $10.36 \% \mathrm{Mn}$ and $4.9 \% \mathrm{Cr}(\times 400)$. 5. Microstructure of cast iron with $14 \cdot 71 \% \mathrm{Mn}$ and $4.85 \% \mathrm{Cr}(\times 400)$. 

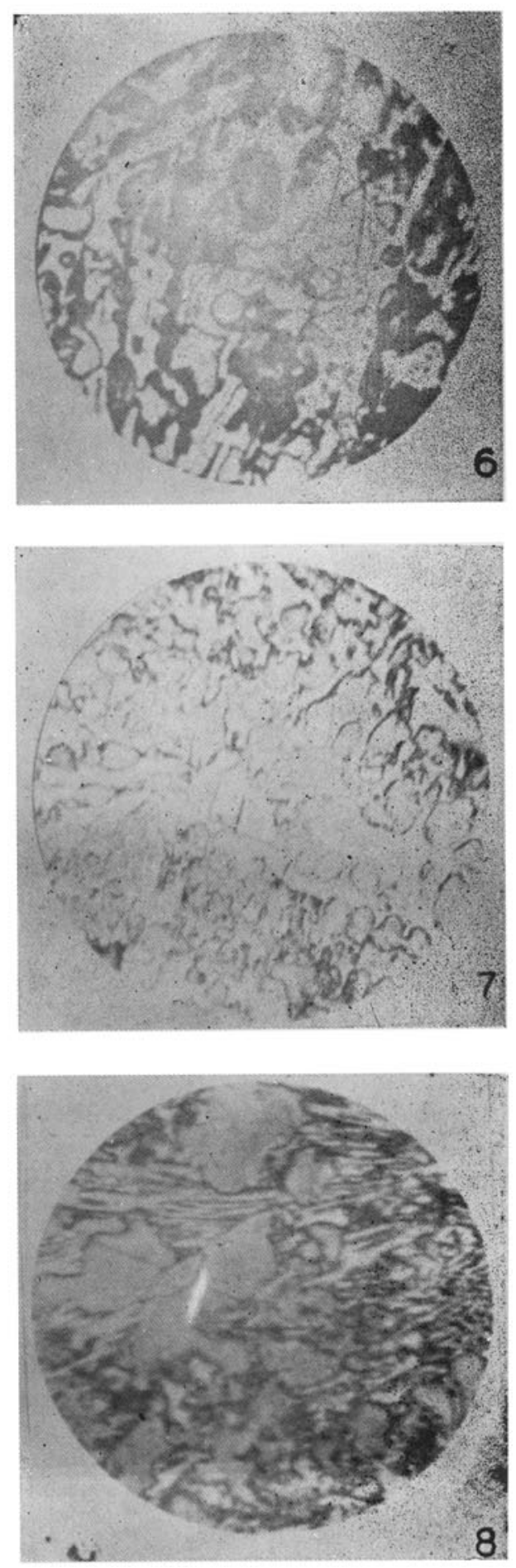

Figures 6, 7 and 8. Microstructures of cast iron. 6. with $4 \cdot 35 \% \mathrm{Mn}$ and $4 \cdot 85 \%$ $\mathrm{Cr}, 7$. with $10.6 \% \mathrm{Mn}$ and $2.95 \% \mathrm{Cr}$ and 8 , with $10.5 \% \mathrm{Mn}$ and $6.92 \% \mathrm{Cr}$ $($ all $\times 400)$. 


\section{References}

Dodd $J$ and Govin G E 1974 Foundry 102 102-105

Norman T E and Loeb C M Jr 1948 Transactions AIME 176490

Norman T E, Solomon A and Doane D V 1959 Mod. Cast. 35104 